\title{
Research on the Reform of College English Teaching From the Perspective of Flipped Classroom
}

\author{
Ling Xiao \\ Changsha Medical University, Changsha City, Hunan Province, 410219, China
}

\author{
Keywords: Flipped classroom; College English; Autonomous learning; Model
}

\begin{abstract}
With the development of modern network information technology, flipped classroom has received a wide attention from foreign language teachers in China as a novel pedagogical mode with unique advantages. As a modern and creative pedagogical mode, flipped classroom boasts many exclusive advantages over traditional classrooms. Based on the author's learning and practical experience, this paper firstly analyzed the connotation and development of the flipped classroom, and then it discussed the advantages of the flipped classroom at college English teaching. Finally, the paper put forward an effective way to implement the flipped classroom.
\end{abstract}

\section{Introduction}

As a kind of brand-new teaching idea and method to subvert the traditional teaching method, the flipped classroom originated in the United States has increasingly become the focus of education reform. Although the flipped classroom has been widely spread and implemented in the United States and has been highly praised and widely recognized by the American teachers and students, the research and application of flipped classroom in China is still in its infancy. Today, the rapid development of China's information technology with the popularization and application of network technology and the effective implementation of the Ministry of Education planning provides a broad platform and a good opportunity for the spread and application of flipped classroom. The introduction of flipped classroom and its application in college English teaching in China, which can break through the predicament of college English teaching and provide convenience for Chinese college students in learning English and deepen the reform of college English teaching fundamentally so that to comprehensively improve the level of college English teaching and college students' comprehensive English ability from the aspects of listening, speaking, reading, writing and translating.

\section{The Connotation and Development of Flipped Classroom}

Flipped classroom is a kind of reverse teaching method based on the traditional teaching form, which refers to the students complete the relevant course of learning and complete the process of knowledge transfer through the teaching of video, audio and other multimedia resources; and then makes learning effect detection through the network according to the teacher's request so that attaches the preliminary processing and absorption of new information. Finally, the students will participate in the interaction process of the physical classroom with the problems encountered in the learning process. More improtantly, it can also achieve the in-depth understanding of the knowledge with skilled and flexible using through classroom discussion, answering questions, cooperative learning, group practice and other forms of diversification.

The concept of flipped classroom was originally proposed by Sylvanus Thayer, aiming at replacing the traditional teaching mode based on teacher's teaching by the interaction between teachers and students. The new teaching mode of anti-tradition advocates the new paradigm of pre-learning and pro-teaching and subvert the indoctrination of teaching thinking at traditional 
classroom. This not only helps to stimulate and enhance students' critical thinking and creative thinking, but also helps students to develop their ability in analyzing and solving problems independently. Since the 21st century, the application of flipped classroom teaching mode has been widely concerned in the United States. In 2011, it was honoured as an important technological revolution in classroom teaching. Flipped classroom has been widely promoted and implemented in many other countries and was widely recognized and praised by teachers and students.

\section{The Advantages of Flipped Classroom at College English Teaching}

Optimize teaching structure and promote teaching the student in accordance with their aptitude. The traditional classroom is a place for teachers to impart knowledge. In the limited time of 45 minutes, the teacher will transfer the knowledge to the students in the largest extent. It is a one-way process of information transfer. This model excessively focuses on the transfer of knowledge from teachers to students; however, it ignores the individual differences and cognitive characteristics of the students as recipients of knowledge. It does not take into account the extent to which the students are able to absorb and internalize the knowledge taught in class.

Flipped classroom makes up the defects of traditional teaching methods, fully mobilizes the enthusiasm of the students and plays the key role of students in English learning. Different students can choose different emphasis in the network learning with enough time to think and learn. There is more time and opportunity to communicate with each other, which is conducive to the development of personalized and differentiated students and is able to meet the needs of different students so that the function of the classroom has been maximized and achieve efficient classroom value appeal with the purpose of earnestly implementing the teaching concept of teaching students in accordance with their aptitude.

Advocate pluralistic interaction and enhance relationship between teacher and student. Traditional classroom adopts the teaching mode led by teachers, and there is a strict hierarchical relationship between teachers and students. The teacher has the absolute right to speak and control in the classroom, and they control all the links and processes in the classroom. However, the students are in a subordinate position, so they absolutely obey the arrangement of teachers without any rights to question or argue with the teacher. To a large extent, the students' critical thinking and creative thinking are restrained, which is not conducive to the cultivation of students' thinking ability and the harmonious development of relationship between teacher and student.

Classroom activities change from teacher's teaching to the interactions of teachers and students, which not only make students ask questions to teachers freely, but also can discuss with other students so that to form a diversified interactive mode of interaction between teachers and students and interactions between students and students. This will effectively enhance the communication between teachers and students. In the process of communication, students' creative thinking, critical thinking, communication and cooperation ability can be effectively improved, and the absorption and internalization of knowledge is also significantly improved.

Integration of quality resources to promote educational equity. At present, there is a serious problem of uneven distribution of educational resources at colleges and universities in china. High quality teaching resources are concentrated in a small number of elite schools so that most students can not be reached. Flipped classroom helps to alleviate the uneven distribution of resources. In the teaching video preparation stage, teachers can use the Internet information technology to search and integrate the quality of teaching resources around the world and integrate it into their curriculum design so that students in different regions, different universities can fully enjoy the quality of teaching resources, effectively reduce regional differences and 
make up the poor effect of foreign language classroom teaching caused by the different teaching methods, teaching level and knowledge structures. Flipped classroom helps to break the traditional monopoly of educational resources to enable students in different countries or regions to get the best quality of teaching resources. With the popularization and development of network information technology, more and more students in remote areas can receive the same education as those in developed areas. The integration and optimization of the classroom teaching resources from flipped classroom are incomparable, which truly achieve the goal of educational equity.

\section{An Effective Way to Implement the Flipped Classroom at College English Teaching}

Defining the role and orientation of Teachers. Teachers should firstly adjust their mentality and change their ideas with approving the new relationship between " teachers and students with equal status” in perception. Teachers should eliminate the idea of hierarchy and freed from the almost absolute right to speak. They are no longer the authority to impart knowledge, but the conductor who help students making autonomous learning and explanation. As a guide, teachers need to understand each student's inner potential and superiority intelligence, grasp the difference of their learning progress and the difference of understanding and master the question of how to provide students with differentiated "one to one" guidance; they also should solve each student's problems in the limited time and space in the classroom and promote the development of individuals with abandoning the original stereotyped popular teaching. These changes have posed great challenges to teachers, so teachers need to improve the ability to master the works; at the same time, they should equip with the comprehensive excellent guidance, including the abilities to integrate resources, judgment, professionalism, business skills, communication skills, collaboration and communication skills, etc.

Improve the information literacy of teachers and students. To achieve the successful application of flipped classroom at college English teaching, both teachers and students should improve their information literacy and computer application skills. First of all, the production of teaching video requires a higher level of teachers' information technology. Only teachers have a certain degree of information technology and computer application skills, integrate the difficulties of the course information elements into short video and design the practice in line with the test, which can achieve the smooth knowledge transmission through micro video and track the progress of the students' autonomous learning and knowledge control. Similarly, only students with a certain level of computer application on the basis of the use of computer terminals, tablet PCs or smart phones and other mobile terminals, can they effectively complete the self-study before class and its pre class practice (namely the online self-test test) and find out the crux of the problem. Therefore, the level of information technology should not be an obstacle to the new mode of College English teaching. Both teachers and students should strengthen their own information technology literacy and computer application level, which is the basis and premise of effective classroom interaction and also is an effective guarantee of concrete practice.

Improve students' autonomous learning ability. The effect of students' autonomous learning micro video course directly affect the implementation and efficiency of the process of knowledge internalization in flipped classroom. Flipped classroom makes the traditional teaching mode of one-way transmission from teachers to the students into knowledge of the reverse inquiry through students watching the micro video. This is a complete transformation and beneficial supplement to the process of knowledge transfer, which also puts forward higher requirements for students' autonomous learning ability and self-discipline. Before class, the students become the automatic regulator of the learning process; namely, students choose time and space on study according to their own learning abilities so that to master the learning content and learning progress and pace. In the class, the high participation with teacher and schoolmate's 
exchange interactions will continue to expand and create new knowledge in a broad range and depth. The improvement of students' autonomous learning ability and the development of individualized learning enable students gain lifelong benefits. Thus, this is not only the fundamental way to improve the effectiveness of college English teaching, but also the only way to realize the sublimation of the students' education from school to life.

\section{Summary}

Aiming at the current emergent situation of college English teaching in china, the introduction and practice of flipped classroom can make up for the defects of college English teaching to a certain extent. Flipped classroom can accurately grasp the objective law of its development, steadily break through the bottleneck of its development, maximize the students' subjective initiative and improve students' learning efficiency and effect, which will design a practical and feasible plan for the current reform and development of college English teaching so that it has injected new vitality into the reform of educational informatization in China.

\section{Acknowledgement}

The Guidance of Categorization and Non Categorization to the Design of Graded Teaching - A Case Study of Directional and Regular Classes in Changsha Medical University. Number: Changsha Medical University Teaching, (2015) 14-22.

\section{References}

[1] Cui Yanhui, Wang Yi. Flipped Classroom and Its Application at College English Teaching [J]. Chinese Audio-visual Education, 2014,(11):116-121.

[2] Li Yu, Zhang Yun. A Probe into the Reform of College English Classroom Teaching [J]. Continuing Education Research, 2013,(05):147-149.

[3] Yuan Hong. College English Teaching Reform From the Perspective of Ecology [J]. Heilongjiang Education(Higher Education Research and Evaluation), 2012,(11):3-4.

[4] Feng Juehua. Dynamic Classroom Teaching: A New Model of College English Classroom Teaching Reform [J]. Education Exploration, 2008,(05):36-37.

[5] Chen Qingsong, Xu Luomai. Autonomous Learning of Foreign Language in College English Teaching [J]. Foreign language circle, 2016,(06):16-23.

[6] Jia Weiguo. Some Thoughts on the Reform of College English Teaching in China [J]. Shandong Foreign Language Teaching, 2015,(02):53-56.

[7] Sun Jingxin, Qu Nini, Wang Baoping. Reform and Practice of College English Classroom Teaching [J]. Journal of Shaanxi Normal University (Philosophy and Social Sciences Edition), 2013,(S2):23-25. 